\title{
ADMINISTRADOR JUDICIAL: PILAR DA LEI DE RECUPERAÇÃO DE EMPRESAS E FALÊNCIA
}

Reginaldo Souza Novaes, Renata Poloni Sanches.

Universidade do Oeste Paulista - UNOESTE, Curso de Direito, Presidente Prudente/SP. E-mail: reginaldo_novaes@hotmail.com

\section{RESUMO}

É difícil a tarefa do administrador judicial, em recuperar e fazer cumprir o plano de recuperação ou de acompanhar a falência da empresa junto aos credores, pois, o profissional habilitado terá de fazer o melhor possível com o mínimo disponível, lidando com situação de crise e escassez de recursos e diretamente com os credores. Sua atuação exige conhecimentos jurídicoadministrativo-contábil para o bom desenvolvimento do plano, a fim de fazer com que o impacto do processo seja minimizado aos credores, empregados e fornecedores, contribuindo para o soerguimento empresarial ou, quando na falência, de reunir o ativo existente afim de realizar o pagamento aos credores. Ao juiz a tarefa de nomear, com sua indicação, tal profissional. Neste contexto, entende-se, tal ato um entrave a boa condução processual.

Palavras-chave: Administrador judicial, lei de recuperação de empresas e falência, Lei 11.101/2005, empresa em crise.

\section{JUDICIAL ADMINISTRATOR: PILLAR OF CORPORATE RECOVERY AND BANKRUPTCY LAW}

\begin{abstract}
The trustee task is difficult $\mathrm{ff}$ the judicial administrator, to recover and enforce the recovery plan or monitor the bankruptcy of the company with creditors, because the qualified professional will have to do the best possible with the least available, coping with crisis and shortage resources and directly with creditors. Its performance requires legal - administrative and accounting expertise for the good development of the plan in order to make the impact of the process is minimized to creditors, employees and suppliers, contributing to the business uplift or when the bankruptcy, to gather active existing in order to make the payment to creditors. The court to appoint, with indications such professional. In this context, it is understood, such an act an obstacle to good procedural driving.
\end{abstract}

Keywords: Judicial administrator, recovery law firms and bankruptcy, Law 11.101 / 2005, a company in crisis. 


\section{INTRODUÇÃO}

A garantia dos credores quanto a seus recebíveis no universo empresarial, é o patrimônio da empresa. Quando ocorre a necessidade de receber qualquer obrigação vencida, esta pode ser satisfeita individualmente quando o patrimônio da empresa devedora for superior a sua dívida, porém, quando o patrimônio for menor que tal (uma demonstração de estado de insolvência), têm-se por mais interessante e justo, que sejam satisfeitas de forma concursal, para que todos os credores tenham em nível as mesmas garantias. Nesta situação constata-se a falência, que objetiva assegurar que cada um dos credores tenha seu recebimento, mesmo que não correspondente à integralidade obrigacional. Com a criação da Lei 11.101/2005, têm-se ainda a possibilidade de, quando viável, proceder a recuperação da empresa, e assim manter mesmo na crise a sua função social.

Conforme Ulhoa (2015), três pressupostos ensejam a instauração do processo denominado falência, quais sejam, a) devedor empresário, b) insolvência, c) sentença declaratória de falência.

A legislação atual - lei 11.101/2.005, arrola os tipos empresariais que estão sob seu véu, sendo que empresas públicas e sociedades de economia mista (LF, 2이 I) ficam desalistadas deste rol, ressalta-se existir ainda os parcialmente excluídos, pois dependem da observância de condições especificas em lei para decretação de falência, como por exemplo, companhias de seguro, sociedades administradoras de consórcios, ou mesmo as instituições financeiras, que terão como responsável do processo extrajudicial o Banco Central, conforme lei 6.024 de 1674.

Adentrando-se no tema em questão, que é a importância do administrador judicial dentro da lei de recuperação de empresas e falência, abstrai-se quem é esse importante personagem jurídico, a sua necessidade é traduzida desde sua nomenclatura "administrador + judicial" que é aquele que administra dentro do âmbito da justiça, a recuperação judicial ou a falência, onde objeto administrado no caso é o interesse geral na empresa, assim, para que todos os interessados tenham seus direitos resguardados, tem-se no administrador o tomador de decisões para melhor aproveitamento do patrimônio restante da empresa, ou mesmo para sua recuperação, que é o melhor cenário imaginável para a empresa em crise.

O administrador judicial é o profissional com dever de transparência quanto a seus atos, de tal forma que devem estes ser embasados por conhecimentos profundos, de forma sistemática nas qualidades gerenciais exigíveis aos administradores empresariais comuns, porém de forma mais acentuada em questões jurídicas, visto que a empresa já se encontra delicada situação judicial, segundo Sanches (2014) são necessários ao administrador judicial:

“(...) Para que se tenha um processo eficiente e eficaz, tanto na parte da empresa quanto na parte da fiscalização, são necessários conhecimentos multidisciplinares, em especial sobre funcionamento da organização, finanças, cenários econômicos, dentre outros. A administração é um dos pilares do processo de recuperação de empresas, e é um dos motivos que a levam a enfrentar problemas, seja na administração, na profissionalização da estrutura organizacional, na falta de capacitação para atuar na administração da empresa, nos vícios decorrentes das empresas familiares com estilo de gestão ultrapassado, entre outros motivos."

Tem-se, assim, no administrador judicial, a caraterização do profissional auxiliar e de confiança do juiz, colaborador externo da justiça, que age em nome próprio para cumprir suas funções como profissional, cuja indicação pelo juiz merece críticas.

Segundo Sanches (2014),

“(...) o peso sob essa escolha é proporcional ao desafio que será acolhido pelo nomeado, acompanhar com afinco e responsabilidade o processo de soerguimento da empresa em crise, tendo crivo para decisões que podem 
ser a essência para o sucesso do procedimento ou para o desmantelamento total empresa."

Ao administrador judicial é exigido transparência em seus atos junto ao juiz, aos credores e ao devedor, tanto na recuperação judicial da empresa em crise quanto na falência da empresa devedora.

Em comparação à lei anterior de falências - lei 7.661/1945, que tratava da falência utilizando o abandonado instituto da concordata, o legislador nesta nova lei trouxe o administrador judicial (que não existia na lei revogada).

A figura que se aproxima de suas funções era a do sindico, o qual era declarado na sentença pela falência dentre os maiores devedores do falido, ou seja, a lei ensejava que a empresa diretamente fosse posta nesse procedimento ao preencher os requisitos pra tal.

Não havia na lei de 1945 a previsão de instrumentos auxiliares a recuperação da empresa e a falência era decididamente o fim da empresa.

De forma contundente a empresa que falia servia de exemplo para que outras não se propusessem a tal situação, era outro o espirito da lei, o qual havia punição exemplar a fim de intimidar empresas a não falir.

Tal lei anterior (Lei no 7.661/45) desconsiderava que no mundo dos negócios as empresas sujeitam-se a situações nas quais podem ter prejuízos que impossibilitem o bom funcionamento e cumprimento de obrigações, desconsiderava ainda o que a nova lei tenta garantir que é a preservação da empresa e a manutenção da função social da mesma, abrangendo desde os empregados até o desenvolvimento socioeconômico da empresa em crise.

Neste sentido, o objetivo deste estudo foi demonstrar a necessidade do administrador judicial, com suas atribuições nos processos que envolvem a lei de recuperação de empresas e falência, permitindo que tal profissional, pessoa física ou jurídica, escolhido pelo juiz, cumpra suas funções de gerir a recuperação judicial em conjunto com o devedor empresário, ou, com o convalescer em falência, do patrimônio da empresa.

\section{METODOLOGIA}

Na obtenção de dados e apresentação referente a discussão do administrador judicial e da problemática de suma importância dentro da recuperação judicial, foi utilizada metodologia indutiva bibliográfica, abrangendo pesquisas inovadoras à Lei de Recuperação e Falência de Empresas 11.101/2.005 de forma a levantar prismas, contextualizar e discutir, de forma crítica, sobre a escolha do administrador judicial.

\section{RESULTADO}

No artigo 22 e seguintes da Lei de recuperação de empresas e falências (Lei no 11.101/2005) têm-se o maior foco deste estudo, que é a demonstração das características necessárias ao administrador judicial, além de suas funções, em ambos os institutos (recuperação de empresa e falência).

O administrador judicial, sob a fiscalização do juiz e do comitê de geral de credores (CGC) colegiado este presidido pelo administrador judicial e funcionando sempre em seções precedidas de convocações aos credores -, é quem consolida as informações sobre a empresa em crise aos credores através de dados do processo em andamento.

É o administrador judicial responsável para enviar correspondência aos constantes no rol de credores, cujo objetivo principal é a verificação e habilitação de créditos no processo.

A lei atual de recuperação de empresas e falência lhe atribui poderes de requerer ao juiz, quando necessário, a convocação da assembleia-geral de credores, além de contratar, perante 
autorização judicial, auxilio profissional a seu trabalho e ainda, manifestar-se em cada procedimento.

Dentro da recuperação de empresas o administrador judicial manifestar-se-á fiscalizando as atividades do devedor referentes ao plano de recuperação judicial, e neste contexto, tanto relatar o caminhar da execução do plano de recuperação apresentado pelo devedor, quanto requerer a falência por constatar irregularidades nos atos do devedor.

No desenvolvimento da recuperação da empresa em crise o administrador é o responsável, juntamente com o devedor por realizar a verificação e habilitação dos créditos, a fim de conforme o plano recuperacional apresentado, fiscalizar os pagamentos aos credores.

No procedimento da falência, tem a responsabilidade de tornar claros os dados do falido, examinando escrituração, disponibilizando, com avisos, de como os credores terão acesso a livros e demais documentos do falido, agindo ainda, para o bom funcionamento processual, recebendo e abrindo correspondência, e participando também na representação da massa falida judicialmente nos processos.

Deverá, o administrador judicial, ser responsável por relatar as causas que ocasionaram a falência, apontando as responsabilidades civis e penais dos envolvidos, e realizar os pagamentos dos credores conforme a ordem de preferência existente na legislação falimentar.

\section{DISCUSSÃO}

Um dos principais instrumentos conferidos pela lei ao Juiz, conforme Ulhoa (2015), para Ihe dar efetividade é a figura do administrador judicial, que deverá ser profissional especializado, com condições mínimas estruturais e financeiras para atuar com independência e autonomia, sendo uma garantia do juízo e dos credores quanto à transparência da verdadeira realidade da crise econômica, financeira e patrimonial em que a empresa requerente atravessa.

Por sua vez, a empresa que não possui capacidade mínima de pagar a remuneração do administrador judicial para que atue nestas condições - eis que já se encontra em estado de insolvência, não será considerada viável para hipótese de deferimento ou prosseguimento do procedimento recuperacional.

Tem-se, neste sentido, de verificar se há chance da empresa se recuperar, e após esse momento deve o juiz dispor de critérios bem embasados, já que a lei em questão deixa a ele toda responsabilidade para a escolha do administrador judicial.

Ao juiz do caso concreto foi conferido todo peso e discricionariedade da escolha do administrador judicial, vislumbrando uma margem legal para que haja falhas, visto que ao se deparar com situação na qual tenha de punir o administrador o juiz, conforme Sanches (2014) "se verá constrangido, ora pois, se fora ele quem escolheu o administrador judicial, como puni-lo?"

Trata-se de difícil tarefa ao magistrado escolher uma figura assim tão importante e com tamanhas responsabilidades no processo de recuperação ou de falência.

E ainda, complementa Sanches (2014):

“A legislação recuperacional e falimentar é falha neste sentido, uma vez que deveria conter a possiblidade de um novo formato para a escolha do administrador judicial através de habilitação em concurso, tendo o juiz uma relação de profissionais vinculados a um rol de aprovados para sua escolha e atuação no processo de recuperação judicial. Ademais, deveriam os aprovados passar pela frequência de um curso de capacitação a fim de assegurar a tais profissionais qualificação especifica a lei em questão, havendo, assim, a profissionalização da função de administrador judicial".

Portanto, apesar da importância do órgão (assim considerado pela legislação recuperacional e falimentar) administrador judicial, muito há que se discutir em torno do tema. 


\section{CONCLUSÃO}

Conclui-se que, com toda a importância do administrador judicial aqui ressaltada, a escolha deveria ser tratada de maneira mais eficaz e transparente.

O peso da decisão de escolha do administrador judicial deve ser retirado do juiz e pondo-o sobre uma forma concursal.

Dentre aqueles profissionais preparados, que já teriam passado por bancas examinadoras e questionários objetivos/dissertativos, os Tribunais teriam acesso as listas de administradores profissionais já habilitados.

Com experiência, conhecimento técnico e prático de nível condizente ao do papel tão relevante quanto esse desempenhado ao administrador judicial, sem que haja vinculo algum com esse profissional e o magistrado, demonstraria maior transparência e menor receio a vícios de afinidades pessoais o que ainda constitui embaraços ao trâmite processual da recuperação de empresas e falência.

\section{REFERENCIAS}

LEI No 11.101, DE 9 DE FEVEREIRO DE 2005 http://www.planalto.gov.br/ccivil 03/ ato20042006/2005/lei/l11101.htm

COELHO, Ulhoa, F. (5/2015). Tratado de direito comercial Volume 7: Falência e recuperação de empresa e direito marítimo, 1 a edição.

. Comentários à Lei de Falências e de recuperação de empresas / Fábio Ulhoa Coelho. - 9. ed. São Paulo : Saraiva, 2015.

MAMEDE, Gladston. Direito Empresarial Brasileiro - Vol. 4 - Falência e Recuperação de Empresas, 8a edição. Atlas, 06/2016.

SANCHES, Renata Poloni. Recuperação Judicial: 0 conflito na prática. In: http://www.conpedi.org.br/publicacoes/66fsl345/90d23xgb/m8ILIKO3WqC9035W.pdf

- A preservação da empresa e a livre concorrência na recuperação judicial. In: http://www.publicadireito.com.br/artigos/?cod=7fb15019103809d7 